\title{
Timing of renal replacement therapy and long-term risk of chronic kidney disease and death in intensive care patients with acute kidney injury
}

Søren Christiansen ${ }^{1 *} \mathbb{D}$, Steffen Christensen², Lars Pedersen ${ }^{1}$, Henrik Gammelager ${ }^{1,3}$, J. Bradley Layton ${ }^{4}$, M. Alan Brookhart ${ }^{4}$ and Christian Fynbo Christiansen ${ }^{1}$

\begin{abstract}
Background: The optimal time to initiate renal replacement therapy (RRT) in intensive care unit (ICU) patients with acute kidney injury (AKI) is unclear. We examined the impact of early RRT on long-term mortality, risk of chronic kidney disease (CKD), and end-stage renal disease (ESRD).

Methods: This cohort study included all adult patients treated with continuous RRT in the ICU at Aarhus University Hospital, Skejby, Denmark (2005-2015). Data were obtained from a clinical information system and populationbased registries. Early treatment was defined as RRT initiation at AKI stage 2 or below, and late treatment was defined as RRT initiation at AKI stage 3. Inverse probability of treatment (IPT) weights were computed from propensity scores. The IPT-weighted cumulative risk of CKD (estimated glomerular filtration rate $<60 \mathrm{ml} / \mathrm{minute} / 1.73 \mathrm{~m}^{2}$ ), ESRD, and mortality was estimated and compared using IPT-weighted Cox regression.

Results: The mortality, CKD, and ESRD analyses included 1213, 303, and 617 patients, respectively. The 90-day mortality in the early RRT group was 53.6\% compared with $46.0 \%$ in the late RRT group (HR 1.24, 95\% Cl 1.03-1.48). The 90-day to 5 -year mortality was $37.7 \%$ and $41.5 \%$ in the early and late RRT groups, respectively ( $\mathrm{HR} 0.95,95 \% \mathrm{Cl}$

$0.70-1.29)$. The 5 -year risk of CKD was $35.9 \%$ in the early RRT group and $44.9 \%$ in the late RRT group (HR $0.74,95 \% \mathrm{Cl}$ $0.46-1.18)$. The 5 -year risk of ESRD was $13.3 \%$ in the early RRT group and $16.7 \%$ in the late RRT group (HR $0.79,95 \% \mathrm{Cl}$ 0.47-1.32).

Conclusions: Early initiation was associated with increased 90-day mortality. In patients surviving to day 90, early initiation was not associated with a major impact on long-term mortality or risk of CKD and ESRD. Despite potential residual confounding due to the observational design, our findings do not support that early RRT initiation is superior to late initiation.
\end{abstract}

Keywords: Acute kidney injury, Chronic kidney disease, End-stage renal disease, Renal replacement therapy, Timing

\footnotetext{
*Correspondence: sorenchristiansen@hotmail.com

'Department of Clinical Epidemiology, Aarhus University Hospital, Olof

Palmes Allé 43-45, 8200 Aarhus N, Denmark

Full list of author information is available at the end of the article
} 


\section{Background}

Acute kidney injury (AKI) occurs in $39-57 \%$ of intensive care unit (ICU) patients, and $6-14 \%$ of ICU patients are treated with renal replacement therapy (RRT) [1-4]. Patients with RRT-treated AKI have a 90-day mortality of $50-60 \%$ and a 5 -year risk of end-stage renal disease (ESRD) of $>10 \%$ [5-8]. The optimal time to initiate RRT remains unclear [9]. There is a theoretical rationale for early initiation of RRT, such as improved control of fluid balance, electrolytes, and acid-base status. However, a treatment strategy of earlier initiation is accompanied by the risk of exposing patients who might have recovered without RRT to RRT and treatment-related complications [10].

Authors of meta-analyses of primarily observational studies have found early RRT initiation to be associated with reduced short-term mortality compared with late RRT initiation $[11,12]$. However, the majority of included studies had methodological limitations, such as small sample sizes or inadequate control of confounding. Results of randomized controlled trials (RCTs) are conflicting, but authors of meta-analyses of pooled data have observed no difference in short-term mortality or RRT dependency [13, 14].

To our knowledge, only two observational studies have assessed mortality beyond day 90 , and none have examined the impact of timing of RRT on risk of chronic kidney disease (CKD) and ESRD $[15,16]$. To address this gap in the literature, we conducted a cohort study to examine the impact of early RRT in ICU patients on 5-year risk of CKD, ESRD, and mortality.

\section{Methods}

\section{Study population and setting}

This cohort study included all patients aged 15 years or older who were treated with continuous RRT in the 13-bed ICU at Aarhus University Hospital, Skejby, Denmark, from January $1^{\text {st }}, 2005$, to January $1^{\text {st }}, 2015$. Patients were admitted from departments of infectious diseases, cardiology, nephrology, urology, gynecology, thoracic surgery, and vascular surgery. The ICU is a university-affiliated, highly specialized referral unit treating cardiac transplant patients, among others, and performing extracorporeal membrane oxygenation (ECMO). Patients treated with RRT were identified in a clinical information system (CIS) database used in the ICU (Picis; Picis Inc., Wakefield, MA, USA). The CIS database contains detailed, real-time, electronically registered data on, among others, treatment with vasopressors and inotropes, mechanical ventilation, hemodynamics, and RRT treatment. Additionally, it contains manually registered data on weight and urine output. All patients were treated using a PRISMA continuous RRT system (GAMBRO DASCO S.p.A., Medolla, Italy) with a prescribed effluent dose of $30 \mathrm{ml} / \mathrm{kg} / \mathrm{h}$. Continuous venovenous hemodiafiltration was used in the vast majority $(>90 \%)$ of patients. Until March 2014, heparin was the standard anticoagulation method, and citrate was used thereafter.

The Danish health care system is tax-funded and provides free and universal health care for all Danish citizens. Every citizen has a Danish civil registration (CPR) number assigned at birth or immigration [17]. Through the CPR number, deterministic individuallevel linkage between clinical and administrative databases is possible. To ensure information on preadmission morbidity and follow-up, we included only patients with a Danish CPR number and who had residency in Denmark [17]. We considered only patients with newly developed severe renal impairment and therefore excluded patients with existing ESRD at ICU admission.

\section{Timing of renal replacement therapy}

The AKI stage was assessed by using the Kidney Disease: Improving Global Outcomes (KDIGO) AKI criteria for plasma creatinine and urine output (measured as volume in $\mathrm{ml} / \mathrm{minute} / \mathrm{kg}$; whichever value gave patients the highest stage) (Table 1) [18]. The creatinine measurements were obtained from a laboratory database [19]. The database contains information on every blood test taken during in- and outpatient visits to public or private hospitals or submitted by general practitioners in the central and northern regions of Denmark (for NPU [Nomenclature for Properties and Units] codes, see Additional file 1: Table S1). The creatinine ratio was calculated using the latest creatinine measurement $24 \mathrm{~h}$ before RRT initiation divided by the baseline creatinine. Baseline creatinine was estimated as the mean of all creatinine measurements from outpatient clinics or visits to the general practitioner from 1 year to 7 days before ICU admission [20]. For patients without outpatient creatinine measurements, the baseline was imputed with the four-variable Modification of Diet in Renal Disease (MDRD) equation (assuming an estimated glomerular filtration rate [eGFR] of $75 \mathrm{ml} /$ minute $/ 1.73 \mathrm{~m}^{2}$ and Caucasian race), as suggested by the KDIGO AKI guideline [18].

The urine output was obtained from the CIS, requiring at least $6 \mathrm{~h}$ of observation time in accordance with the KDIGO AKI criteria (Table 1) [18]. To compute urine output per kilogram of body weight, we used the average weight during the ICU stay. Patients who could not be evaluated for their urine output owing to $<6 \mathrm{~h}$ of observation time, no diuresis measurements in the specified time period before RRT, or no recorded weight, were assigned an AKI stage based on the creatinine measurements only.

Timing of RRT was defined as early if treatment was initiated at AKI stage 2 or below, including patients not meeting the AKI criteria. Late initiation of RRT was defined as AKI stage 3 at the time of RRT initiation. 
Table 1 Definition of early and late renal replacement therapy

\begin{tabular}{|c|c|c|c|}
\hline Group & $\begin{array}{l}\text { KDIGO } \\
\text { stage }\end{array}$ & Creatinine & Urine output \\
\hline \multirow[t]{3}{*}{ Early RRT } & & $\begin{array}{l}\text { Patients not meeting AKI } \\
\text { criteria }\end{array}$ & \\
\hline & 1 & $\begin{array}{l}1.5-1.9 \text { times baseline } \\
\text { or } \geq 26.5 \mu \mathrm{mol} / \mathrm{L} \\
(0.3 \mathrm{mg} / \mathrm{dl}) \text { increase in } \\
\text { creatinine within } 48 \mathrm{~h}\end{array}$ & $\begin{array}{l}<0.5 \mathrm{ml} / \mathrm{kg} / \mathrm{h} \\
\text { for } 6-12 \mathrm{~h}\end{array}$ \\
\hline & 2 & 2.0-2.9 times baseline & $\begin{array}{l}<0.5 \mathrm{ml} / \mathrm{kg} / \mathrm{h} \\
\text { for }>12 \mathrm{~h}\end{array}$ \\
\hline Late RRT & 3 & $\begin{array}{l}3.0 \text { times baseline or } \\
\text { creatinine } \geq 354 \mu \mathrm{mol} / \mathrm{L} \\
(4.0 \mathrm{mg} / \mathrm{dl})^{\mathrm{a}}\end{array}$ & $\begin{array}{l}<0.3 \mathrm{ml} / \mathrm{kg} / \mathrm{h} \\
\text { for }>24 \mathrm{~h} \text { or } \\
\text { anuria for } \geq 12 \mathrm{~h}\end{array}$ \\
\hline
\end{tabular}

Abbreviations: AKI Acute kidney injury, KDIGO Kidney Disease: Improving Global Outcomes, RRT Renal replacement therapy

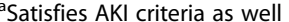

\section{Chronic kidney disease, end-stage renal disease, and mortality}

CKD was defined as at least two eGFR measurements $<60 \mathrm{ml} /$ minute $/ 1.73 \mathrm{~m}^{2}$ separated by $>90$ days [21]. The eGFR was estimated from creatinine measurements using the four-variable MDRD equation (assuming Caucasian race) using only outpatient blood samples to avoid inclusion of creatinine measurements performed during hospitalization with acute illness.

ESRD was defined as treatment with chronic RRT or kidney transplant $>90$ days after initiation of RRT in the ICU and was obtained from the Danish National Patient Registry (DNPR). The DNPR contains information on all nonpsychiatric admissions since 1977 and outpatient and emergency visits since 1995. The data include the type of admission (elective or acute), procedures performed, and up to 20 diagnoses given by the physician at discharge, using the Tenth Revision of the International Classification of Diseases since 1994 (Additional file 1: Table S1) [22]. With CKD and ESRD as outcomes of interest, we included both patients who had renal recovery and later developed the outcome and patients without renal recovery.

Time of death was obtained from the Danish Civil Registration system. The registry is updated daily and contains complete information since 1968 on vital status, emigration, and residency [17].

\section{Covariates}

Information on preadmission morbidity 10 years before ICU admission was obtained from the DNPR and included diagnoses assigned after an in- or outpatient visit, except visits to the emergency department to increase validity [22]. We thus included previous diagnoses of renal disease, diabetes (types 1 and 2), congestive heart failure, myocardial infarction, cerebrovascular disease, chronic pulmonary disease, liver disease, periphery vascular disease, malignant solid tumors, lymphoma, leukemia, and metastatic solid tumors, all of which are considered accurate [22]. Using the DNPR, patients were categorized as nonsurgical, elective noncardiac surgical, acute noncardiac surgical, elective cardiac surgical, and acute cardiac surgical, dependent on their type of admission and surgery performed within a period from $24 \mathrm{~h}$ before ICU admission until RRT initiation [23]. Information on mechanical ventilation was obtained from the DNPR. Using information from the laboratory database and the CIS, we computed the patients' Sequential Organ Failure Assessment (SOFA) score on the basis of worst values $24 \mathrm{~h}$ before initiation of RRT, not considering the Glasgow Coma Scale score and renal function (i.e., creatinine level) [24]. Missing or not measured physiological parameters included in the SOFA score were considered normal. The latest potassium and sodium measurements within $24 \mathrm{~h}$ before RRT initiation were obtained from the laboratory database [19].

\section{Statistical analysis}

The patient's characteristics, including demography, other ICU treatments, laboratory values, and time of treatment, were tabulated for the early and late initiation groups. Continuous variables were presented as means with standard deviations (SD) or medians with interquartile intervals (IQI), as appropriate. Categorical variables were presented as frequencies and percentages. We followed patients until outcome of interest, emigration, 5 years from RRT initiation, or censoring on January $1^{\text {st }}, 2016$, whichever came first. Owing to differences in follow-up requirements and outcome definitions, we performed an analysis for each outcome: CKD, ESRD, and death. By definition, chronic renal impairment should last $>90$ days [21]. Therefore, we included only patients who survived until day 90 when we examined the impact on CKD and ESRD. Furthermore, to examine the impact of early and late RRT on the risk of CKD, we included only patients having residency in a Danish region covered by the laboratory database (i.e., the central and northern regions of Denmark) and without evidence of existing renal disease. Prior renal disease was defined as at least two outpatient eGFR measurements $<60 \mathrm{ml} /$ minute $/ 1.73 \mathrm{~m}^{2}$ at least 90 days apart during the year before ICU admission or a diagnosis of any renal disease before admission [19].

To adjust for potential confounders, propensity scores were estimated using a multivariable logistic regression model including all the prespecified characteristics presented for each cohort [25]. The included variables are presented in Table 2 for the mortality analysis, with the CKD and ESRD analyses presented in Additional file 2: Table S2 and Additional file 3: Table S3, respectively. Continuous variables were included in the model with a restricted cubic spline function with four knots. From the propensity scores, we computed inverse probability of treatment (IPT) weights; when these weights are 
applied to a population, they create a pseudo-population in which exposure status is independent of measured covariates $[26,27]$. The covariate balance in the full and IPT-weighted cohorts was evaluated with standard mean differences [26]. For each outcome, we estimated the IPT-weighted cumulative risk. With ESRD and CKD as outcomes of interest, we accounted for death as a competing risk. The HRs were estimated using a crude and IPT-weighted Cox proportional hazards regression with the $95 \% \mathrm{CI}$ estimated using a robust variance estimator. The assumption of proportional hazards was checked graphically by $\log (-\log )$ plots. As sensitivity analyses, we repeated the analyses for each outcome after exclusion of patients treated with ECMO in addition to RRT during ICU admission. Additionally, we performed a fifth-percentile asymmetrical trim to remove the potential influence of unmeasured confounding in the tails of the propensity score distributions [28].

Analyses were performed using the Stata version 14.1 statistical software package (StataCorp LP, College Station, TX, USA). The study was approved by the Danish Data Protection Agency (record number 2015-57-0002, Aarhus University record number 2016-051-000001-432).

\section{Results}

\section{Descriptive results}

In the 10-year study period, 1369 adult patients were treated with RRT. We excluded 69 patients with previous ESRD, 31 with residency outside Denmark, and 14 who could not be linked to the DNPR. We had to exclude 42 patients because of missing information on laboratory values prior to RRT initiation. This gave us a study population of 1213 patients (Fig. 1). The total follow-up time was 1994 person-years. The median time from ICU admission to RRT initiation was 18.9 (IQI 8.3-35.2) $\mathrm{h}$ in the early group compared with 32.8 (IQI $7.8-79.8) \mathrm{h}$ in the late group.

Characteristics of the full and IPT-weighted cohort with mortality as an outcome are presented in Table 2 . In the full cohort, early and late RRT were initiated in $621(51.2 \%)$ and $592(48.8 \%)$ patients, respectively. The groups had similar age and sex distributions; however, early initiators had a higher SOFA score (5.5 vs. 4.8) and were more likely to have received acute cardiac surgery $(30.3 \%$ vs. $22.3 \%)$. A higher proportion of patients in the late group were treated in the beginning of the study period (2005-2006). In the IPT-weighted cohort, demographics, use of other organ-supportive treatments, laboratory values, preadmission morbidities, and year of treatment were similarly distributed in both groups. The most frequent preadmission morbidities were renal disease, congestive heart failure, and vascular disease.
Measured baseline creatinine was available in 829 (68.3\%) patients. Patients without measured baseline creatinine were equally distributed between both treatment groups, and they were younger and had less preadmission morbidity than those with baseline creatinine (Additional file 4: Table S4). AKI stage was assessed by urine output and creatinine criteria in $682(56.2 \%)$ patients and by creatinine criteria only in 531 (43.8\%) patients.

\section{Mortality}

In the crude analysis, 90-day mortality was $52.5 \%$ and $45.6 \%$ in the early and late groups, respectively (Table 3 ). The corresponding HR was estimated as 1.24 (95\% CI 1.06-1.46) in the early group compared with the late group. In the IPT-weighted analysis, the 90-day mortality was $53.6 \%$ in the early group and $46.0 \%$ in late group (Table 3 and Fig. 2). This corresponds to a HR of 1.24 (95\% CI 1.03-1.48). In the crude analysis, 90-day to 5year mortality was $36.1 \%$ in the early group and $42.6 \%$ in the late group. The corresponding HR was estimated to 0.89 (95\% CI 0.68-1.17). In the IPT-weighted analysis, the 90 -day to 5 -year mortality was $37.7 \%$ in the early group and $41.5 \%$ in the late group with a corresponding HR of 0.95 (95\% CI 0.70-1.29).

\section{Chronic kidney disease}

With CKD as outcome, 303 patients were eligible for the analysis (Fig. 1). The patients' characteristics were equally distributed between the early and late groups after IPT weighting (Additional file 2: Table S2). Of the 141 patients who initiated RRT early, 119 (84.4\%) had 2 or more outpatient creatinine measurements after hospital discharge compared with 146 (90.1\%) of the 162 patients who initiated RRT late. In the crude analysis, the 5-year risk of CKD was $43.6 \%$ and $45.0 \%$ in the early and late groups, respectively (Table 3 ). This corresponds to a HR of 0.95 (95\% CI $0.67-1.34$ ). In the IPTweighted analysis, the 5 -year risk of CKD was $35.9 \%$ in the early group and $44.9 \%$ in the late group with a corresponding HR of 0.74 (95\% CI 0.46-1.18) (Table 3 and Fig. 3).

\section{End-stage renal disease}

With ESRD as outcome, the analysis included 617 patients (Fig. 1). After IPT weighting, the patients' characteristics were equally distributed between the early and late groups (Additional file 3: Table S3). In the crude analysis, the 5-year risk of ESRD was $13.9 \%$ and $14.4 \%$ in the early and late groups, respectively (Table 3). This corresponds to a HR of 0.96 (95\% CI $0.62-1.48)$. In the IPT-weighted analysis, the 5-year risk of ESRD was $13.3 \%$ in the early group and $16.7 \%$ in the late group (Table 3 and Fig. 4). This corresponds to a HR of 0.79 (95\% CI 0.47-1.32). 
Table 2 Characteristics for the full and inverse probability of treatment-weighted cohort with mortality as outcome

\begin{tabular}{|c|c|c|c|c|c|c|}
\hline & \multicolumn{2}{|l|}{ Full cohort } & \multirow[b]{2}{*}{ SMD } & \multicolumn{2}{|l|}{ IPT-weighted cohort } & \multirow[b]{2}{*}{ SMD } \\
\hline & Early RRT $(n=621)$ & Late RRT $(n=592)$ & & Early RRT $(n=621)$ & Late RRT $(n=592)$ & \\
\hline \multicolumn{7}{|l|}{ Demographics } \\
\hline Age, years, median (|QI) & $67.7(58.5-75.3)$ & $69.0(59.3-75.8)$ & -0.09 & $68.1(59.5-76.6)$ & $68.7(58.1-75.5)$ & 0.03 \\
\hline Male sex, n (\%) & $419(65.5)$ & $419(70.8)$ & -0.11 & $425(68.5)$ & $401(67.7)$ & 0.02 \\
\hline \multicolumn{7}{|l|}{ Surgical status, $n$ (\%) } \\
\hline Nonsurgical & $229(36.9)$ & $281(47.5)$ & -0.22 & $261(42.1)$ & $248(42.0)$ & -0.02 \\
\hline Noncardiac surgery, elective & $37(6.0)$ & $47(7.9)$ & -0.08 & $42(6.7)$ & $43(7.3)$ & -0.02 \\
\hline Noncardiac surgery, acute & $67(10.8)$ & $66(11.1)$ & -0.01 & $67(10.8)$ & $65(11.0)$ & -0.00 \\
\hline Cardiac surgery, elective & $100(16.1)$ & $66(11.1)$ & 0.14 & $84(13.5)$ & $74(12.5)$ & 0.03 \\
\hline Cardiac surgery, acute & $188(30.3)$ & $132(22.3)$ & 0.18 & $167(26.8)$ & $161(27.3)$ & -0.01 \\
\hline SOFA score, mean (SD) & $5.5(2.4)$ & $4.8(2.5)$ & 0.29 & $5.2(2.5)$ & $5.2(2.5)$ & 0.01 \\
\hline \multicolumn{7}{|l|}{ ICU treatments, $n(\%)$} \\
\hline Vasopressors or inotropes & $555(89.4)$ & $491(82.9)$ & 0.19 & $543(87.4)$ & $513(86.6)$ & 0.02 \\
\hline Mechanical ventilation & $475(76.5)$ & $420(70.9)$ & 0.13 & $460(74.0)$ & $441(74.5)$ & -0.01 \\
\hline Extracorporeal membrane oxygenation & $84(13.5)$ & $40(6.8)$ & 0.23 & $67(10.7)$ & $65(11.0)$ & -0.01 \\
\hline \multicolumn{7}{|l|}{ Laboratory values } \\
\hline Creatinine, baseline, $\mu \mathrm{mol} / \mathrm{L}$, median (IQI) & $94.9(82.0-117.0)$ & $90.7(73.7-102.2)$ & 0.19 & $93.2(76.8-115.0)$ & $92.0(76.8-111.7)$ & 0.01 \\
\hline Potassium, mmol/L, median (IQI) & $4.4(3.9-5.0)$ & $4.5(4.1-5.1)$ & -0.17 & $4.4(4.0-5.0)$ & $4.5(4.0-5.0)$ & -0.04 \\
\hline Sodium, mmol/L, mean (SD) & $139.3(7.0)$ & $138.8(7.2)$ & 0.06 & $138.9(7.1)$ & $138.8(7.0)$ & 0.00 \\
\hline \multicolumn{7}{|l|}{ Preadmission morbidity, n (\%) } \\
\hline Renal disease & $178(28.7)$ & $208(35.1)$ & -0.14 & $198(31.9)$ & $188(31.8)$ & 0.00 \\
\hline Diabetes & $101(16.3)$ & $107(18.1)$ & -0.05 & $108(17.4)$ & $104(17.5)$ & -0.00 \\
\hline Congestive heart disease & $180(29.0)$ & $120(20.3)$ & 0.20 & $161(25.9)$ & $153(25.9)$ & -0.00 \\
\hline Myocardial infarction & $154(24.8)$ & $136(23.0)$ & 0.04 & $149(24.0)$ & $148(25.0)$ & -0.02 \\
\hline Cerebrovascular disease & $80(12.9)$ & $86(14.5)$ & -0.05 & $83(13.3)$ & $76(12.9)$ & 0.01 \\
\hline Chronic pulmonary disease & $113(18.2)$ & $90(15.2)$ & 0.08 & $101(16.3)$ & $92(15.6)$ & 0.02 \\
\hline Liver disease & $21(3.4)$ & $23(3.9)$ & -0.03 & $22(3.6)$ & $21(3.5)$ & 0.00 \\
\hline Vascular disease & $172(27.7)$ & $161(27.2)$ & 0.01 & $180(29.1)$ & $164(27.7)$ & 0.03 \\
\hline Tumor & $68(11.0)$ & $95(16.0)$ & -0.15 & 85 (13.7) & $81(13.7)$ & -0.00 \\
\hline Lymphoma & $9(1.4)$ & $6(1.0)$ & 0.04 & $8(1.3)$ & $9(1.5)$ & -0.01 \\
\hline Leukemia & $7(1.1)$ & $5(0.8)$ & 0.03 & $6(0.9)$ & $7(1.1)$ & -0.02 \\
\hline Metastasis & $16(2.6)$ & $17(2.9)$ & -0.02 & $16(2.5)$ & $17(2.9)$ & -0.03 \\
\hline \multicolumn{7}{|l|}{ Year of treatment, $n(\%)$} \\
\hline 2005-2006 & $95(15.3)$ & $149(25.2)$ & -0.25 & $121(19.5)$ & $115(19.4)$ & -0.04 \\
\hline $2007-2008$ & $101(16.3)$ & $120(20.3)$ & -0.10 & $112(18.0)$ & $106(18.0)$ & -0.00 \\
\hline 2009-2010 & $141(22.7)$ & $93(15.7)$ & 0.18 & 119 (19.1) & $119(20.1)$ & -0.03 \\
\hline 2011-2012 & $158(25.4)$ & $94(15.9)$ & 0.24 & $132(21.3)$ & $124(20.9)$ & 0.01 \\
\hline 2013-2014 & $126(20.3)$ & $136(23.0)$ & -0.07 & $138(22.1)$ & $128(21.7)$ & 0.01 \\
\hline
\end{tabular}

Abbreviations: ICU Intensive care unit, IPT Inverse probability of treatment, IQI Interquartile interval, RRT Renal replacement therapy, SMD Standard mean difference, SOFA Sequential Organ Failure Assessment, SD Standard deviation

\section{Sensitivity analyses}

After exclusion of 149 patients treated with ECMO during ICU admission, the results were similar (Additional file 5: Table S5). Furthermore, after a fifth percentile asymmetrical trimming, the results of the analyses with mortality and CKD as outcomes of interest were similar (Additional file 5: Table S5), although for the ESRD outcome, the HR was attenuated from 0.79 (95\% CI $0.47-$ 1.32 ) to 1.02 (95\% CI $0.59-1.75)$, indicating some treatment heterogeneity and possible residual confounding. 


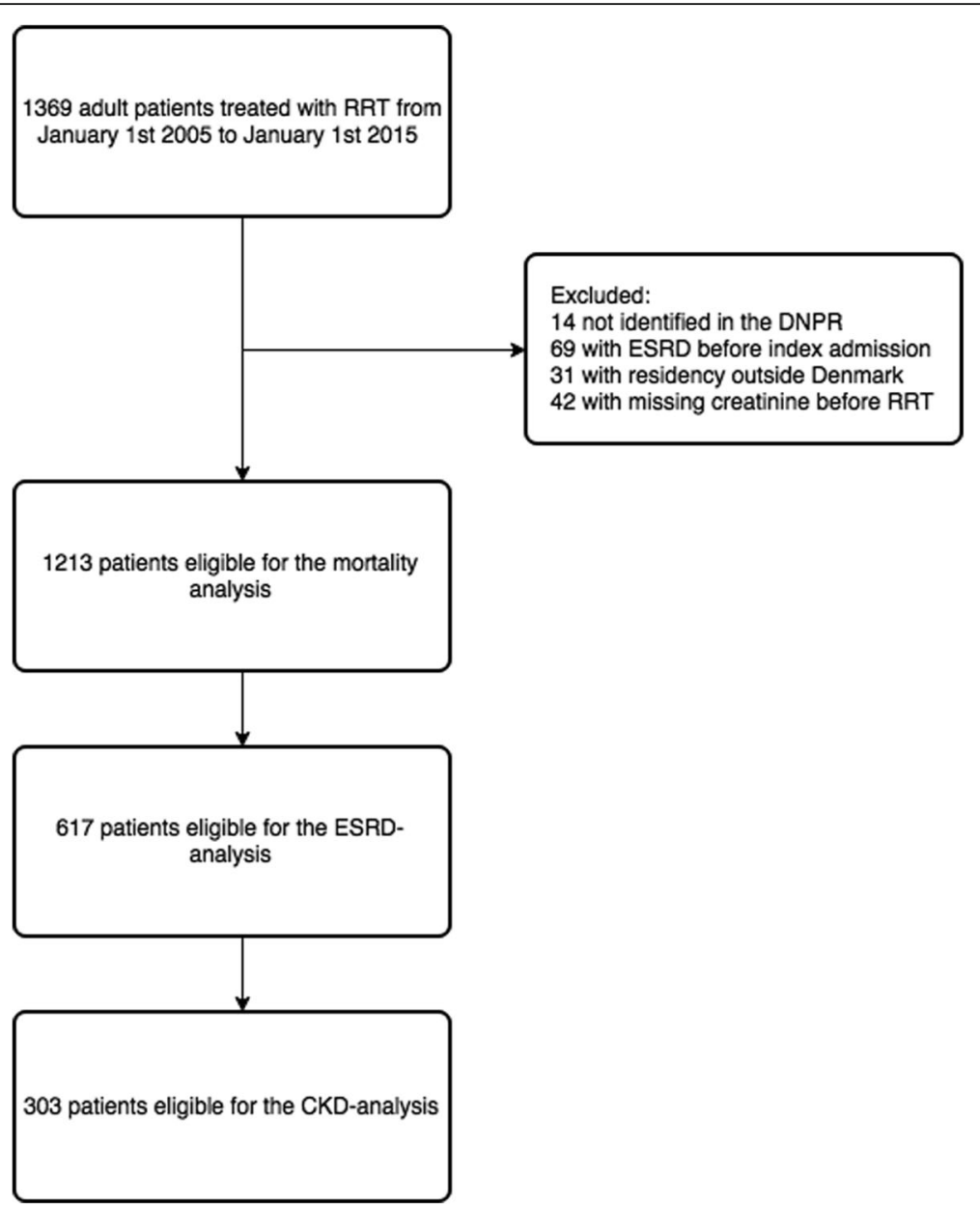

Fig. 1 Flowchart of eligible patients included in the analyses. CKD Chronic kidney disease, DNPR Danish National Patient Registry, ESRD End-stage renal disease, RRT Renal replacement therapy

\section{Discussion}

Using data collected from high-quality clinical and administrative registries, we found no clear evidence that early initiation of RRT in ICU patients was associated with improved long-term clinical outcomes. Early initiation of RRT was not associated with decreased long-term risk of CKD or ESRD. Early initiation was associated with increased shortterm mortality but not with long-term mortality. Despite the use of advanced methods, we cannot rule out the influence of residual confounding.

Table 3 Crude and inverse probability of treatment-weighted cumulative risks and hazard ratios

\begin{tabular}{|c|c|c|c|c|c|c|}
\hline & \multicolumn{3}{|c|}{ Crude analysis } & \multicolumn{3}{|c|}{ IPT-weighted analysis } \\
\hline & Early RRT, \% & Late RRT, \% & HR $(95 \% \mathrm{Cl})$ & Early RRT, \% & Late RRT, \% & $\mathrm{HR}(95 \% \mathrm{Cl})$ \\
\hline \multicolumn{7}{|l|}{ Mortality, $n=1213$} \\
\hline 0 to 90 days & 52.5 & 45.6 & $1.24(1.06-1.46)$ & 53.6 & 46.0 & $1.24(1.03-1.48)$ \\
\hline 90 days to 5 years & 36.1 & 42.6 & $0.89(0.68-1.17)$ & 37.7 & 41.5 & $0.95(0.70-1.29)$ \\
\hline 0 to 5 years & 69.7 & 68.8 & NA & 71.1 & 68.4 & NA \\
\hline \multicolumn{7}{|l|}{$C K D, n=303$} \\
\hline 90 days to 5 years & 43.6 & 45.0 & $0.95(0.67-1.34)$ & 35.9 & 44.9 & $0.74(0.46-1.18)$ \\
\hline \multicolumn{7}{|l|}{ ESRD, $n=617$} \\
\hline 90 days to 5 years & 13.9 & 14.4 & $0.96(0.62-1.48)$ & 13.3 & 16.7 & $0.79(0.47-1.32)$ \\
\hline
\end{tabular}




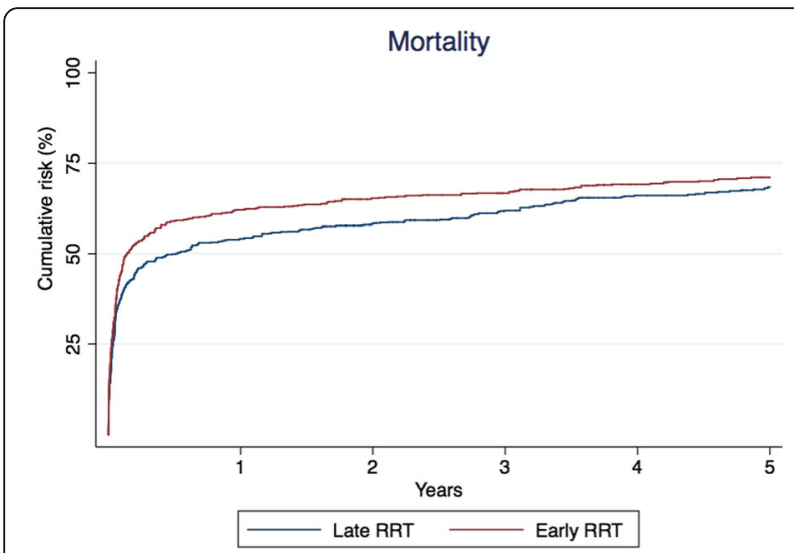

Fig. 2 Inverse probability of treatment-weighted cumulative mortality for 0 to 90 days, HR 1.24 (95\% Cl 1.03-1.48); for 90 days to 5 years, HR 0.95 (95\% Cl 0.70-1.29). RRT Renal replacement therapy

\section{Existing studies}

Until recently, existing studies on timing of RRT in ICU patients with AKI were mainly observational, with few RCTs conducted. Researchers in observational studies have used a wide array of parameters to define timing, such as blood urea nitrogen, creatinine, urine output, fluid overload, traditional indications for RRT (e.g., hyperkalemia), time from ICU admission, time from AKI diagnosis, and according to the RIFLE (risk, injury, failure, loss, end-stage renal disease) criteria [11]. The results derived from these observational studies on short-term mortality are conflicting, but after pooling the results of both observational and RCTs, metaanalyses in general favor early RRT initiation [11, 12]. However, because of the heterogeneity in definitions of early and late RRT and the methodological limitations of included studies, the results should be interpreted with caution. Wierstra et al. found that low-quality studies

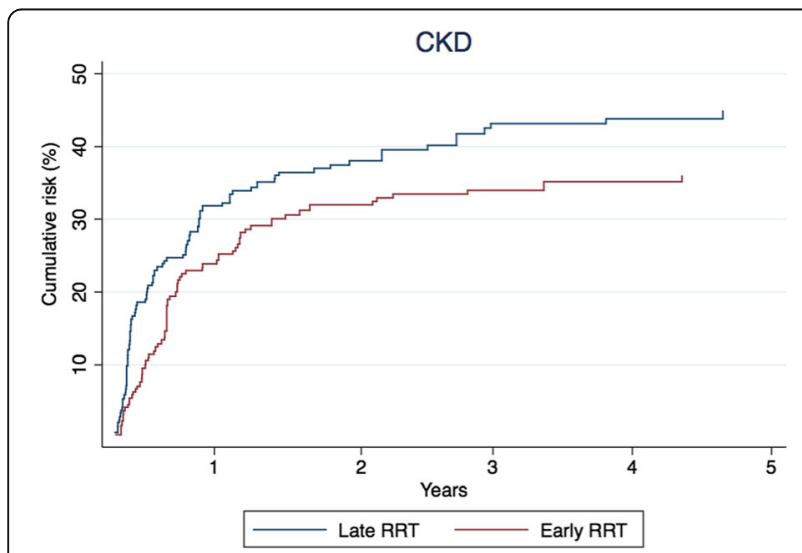

Fig. 3 Inverse probability of treatment-weighted cumulative risk of chronic kidney disease for 90 days to 5 years, HR 0.74 (95\% Cl 0.46-1.18). CKD Chronic kidney disease, RRT Renal replacement therapy

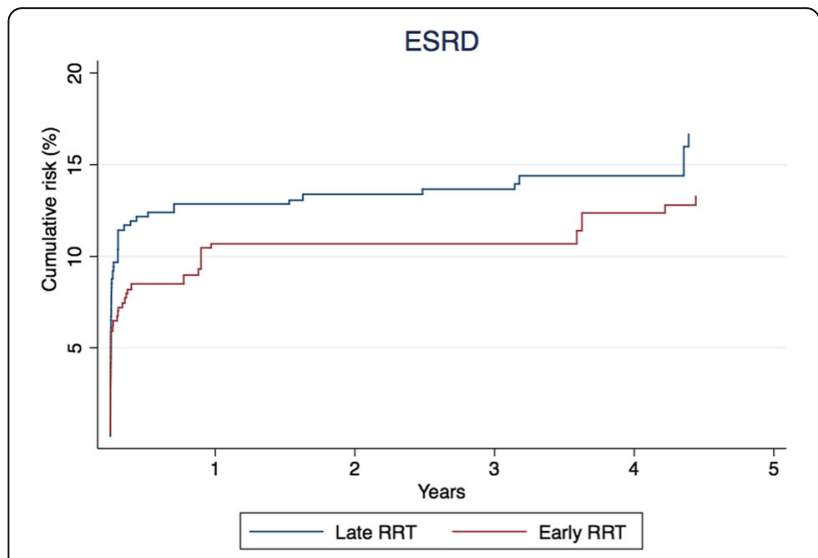

Fig. 4 Inverse probability of treatment-weighted cumulative risk of end-stage renal disease for 90 days to 5 years, HR 0.79 ( $95 \%$ Cl $0.47-$ 1.32). ESRD End-stage renal disease, RRT Renal replacement therapy

(mainly observational studies) favored early initiation (OR 0.47, 95\% CI 0.34-0.65; early compared with late); however, in high-quality studies (mainly RCTs), early RRT did not statistically significantly reduce mortality (OR 0.67, 95\% CI 0.38-1.15) [11].

In the majority of conducted RCTs, investigators have defined timing according to the presence of absolute indications [13]. In the recent multicenter AKIKI (Artificial Kidney Initiation in Kidney Injury) trial, 619 patients with AKI stage 3 who required mechanical ventilation, catecholamine infusion, or both were randomized either to immediate RRT (early) or to treatment being withheld until absolute indications developed (late) [29]. The authors observed no difference in 60-day mortality or RRT dependency. These findings are supported by meta-analyses including only RCTs on timing of RRT $[13,14]$. The single-center ELAIN (Early versus Late Initiation of Renal-Replacement Therapy in Critically Ill Patients with Acute Kidney Injury) trial is the only RCT in which researchers have observed a lower short-term mortality with early initiation [30]. The authors randomized 231 patients with AKI stage 2 and plasma neutrophil gelatinase-associated lipocalin $>150 \mathrm{ng} / \mathrm{ml}$ to early RRT treatment (initiated within $8 \mathrm{~h}$ of diagnosis of AKI stage 2) or to late RRT treatment (within $12 \mathrm{~h}$ of AKI stage 3 diagnosis or if absolute indications developed). The authors found a reduced 90-day mortality with early initiation (HR 0.66, 95\% CI 0.45-0.97); however, no difference in RRT dependency at day 90 was found.

No RCTs and few observational studies have assessed outcomes beyond day 90. Evaluating long-term outcomes is important because AKI is associated with a significant impact on long-term morbidity and mortality [8]. Researchers in two studies have examined the association between timing of RRT and mortality beyond day 90. Park et al. classified 607 patients as early or late 
initiators based on the median 6-h urine output [15]. Carl et al. defined 147 nonsurgical ICU patients as early or late initiators if their blood urea nitrogen was below or above $100 \mathrm{mg} / \mathrm{dl}(35 \mathrm{mmol} / \mathrm{L})$, respectively [16]. In contrast to the present study, both of these previous studies demonstrated that early initiation was associated with reduced mortality; however, the interpretation of these studies was hampered by lack of control for important potential confounders.

\section{Strengths and limitations}

Our study has some limitations that need to be considered when interpreting the results. First, we were able to include only patients who were treated with RRT. The lack of patients in the comparison group with AKI stage 2 (and thus potentially early initiators) who regained their renal function without RRT may have introduced bias. Second, baseline creatinine was available for $68.2 \%$ of the patients, with the remainder being estimated with the MDRD equation. This method may lead to slight over- and underestimation of the AKI stage [31-33]. Because the proportion of patients without available baseline creatinine were equally distributed between early and late RRT, any misclassification of AKI stage would most likely bias the estimates toward the null. Examination of patients with missing baseline creatinine showed that they were younger and had less comorbidity. Therefore, we found that imputation using the MDRD equation was reasonable. Third, we were able to obtain information on urine output in slightly more than half of the patients, with the remainder being staged only according to their creatinine ratio. This may have led to misclassification of the early and late initiation groups and may have biased the estimates. Fourth, because CKD can be present without symptoms, our outcome is dependent upon patients having an outpatient blood samples with creatinine taken. A large proportion of the patients included in the CKD analysis had two or more outpatient measurements, and we therefore find it plausible that we identified the vast majority of patients with CKD. Also, we have no reason to believe that AKI stage at initiation of RRT would impact health care vigilance after discharge, and therefore it cannot explain the observed results. Last, as with all observational studies, there still is a risk of residual confounding; however, we were able to adjust for demographic characteristics, detailed data on other ICU treatments, and laboratory values at initiation of RRT.

\section{Conclusions}

Our findings do not support that early RRT initiation is superior to late initiation. Although early RRT was associated with increased short-term mortality, we found no association between timing and long-term outcomes.
This study extends current knowledge on timing of RRT and short-term mortality by providing estimates of the impact on long-term mortality and risk of CKD and ESRD.

\section{Additional files}

\author{
Additional file 1: Table S1. Codes used in the present study.
}

(DOC $44 \mathrm{~kb}$ )

Additional file 2: Table S2. Characteristics for the full and IPT-weighted cohort with CKD as outcome. (DOC $67 \mathrm{~kb}$ )

Additional file 3: Table S3. Characteristics for the full and IPT-weighted cohort with ESRD as outcome. (DOC $78 \mathrm{~kb}$ )

Additional file 4: Table S4. Description of patients with and without baseline creatinine. (DOC $53 \mathrm{~kb}$ )

Additional file 5: Table S5. Sensitivity analyses. (DOC $41 \mathrm{~kb}$ )

\section{Abbreviations}

AKI: Acute kidney injury; AKIKI: Artificial Kidney Initiation in Kidney Injury trial; CIS: Clinical information system; CKD: Chronic kidney disease; CPR: Danish civil registration number; DNPR: Danish National Patient Registry; ECMO: Extracorporeal membrane oxygenation; eGFR: Estimated glomerular filtration rate; ELAIN: Early versus Late Initiation of Renal-Replacement Therapy in Critically III Patients with Acute Kidney Injury trial; ESRD: End-stage renal disease; ICU: Intensive care unit; IPT: Inverse probability of treatment; IQI: Interquartile interval; KDIGO: Kidney Disease: Improving Global Outcomes; MDRD: Modification of Diet in Renal Disease; NPU: Nomenclature for Properties and Units; RCT: Randomized controlled trial; RIFLE: Risk, injury, failure, loss, end-stage renal disease criteria; RRT: Renal replacement therapy; SD: Standard deviations; SMD: Standard mean difference; SOFA: Sequential Organ Failure Assessment

\section{Acknowledgements}

This study was made possible through financial support from the Danish Council for Independent Research (record number 6110-00587A) and University of Copenhagen foundation for medical students (record number A5147).

\section{Funding}

This study was funded by a scholarship from the Danish Council for Independent Research (record number 6110-00587A) and from the University of Copenhagen foundation for medical students (record number A5147). The funding sources had no role in the design of the study; in the collection, analysis, and interpretation of data; or in the writing of the manuscript.

\section{Availability of data and materials}

Parts of the data that support the findings of this study are available from Statistics Denmark, but restrictions apply to the availability of these data, which were used under license for the present study and so are not publicly available.

\section{Authors' contributions}

SChristi, CFC, HG, and SChriste conceived of the study idea and designed the study. SChristi, CFC, LP, and SChriste collected the data. SChristi, CFC, JBL,

and MAB performed the statistical analyses. All authors interpreted the data. SChristi wrote the first draft of the manuscript. All authors critically reviewed and edited the manuscript, and all authors read and approved the final version.

\section{Ethics approval and consent to participate}

The study was approved by the Danish Data Protection Agency (record number 2015-57-0002, Aarhus University record number 2016-051-000001-432). No consent for patient participation was needed.

Consent for publication

No consent for publication was needed. 


\section{Competing interests}

The authors declare that they have no competing interests.

\section{Publisher's Note}

Springer Nature remains neutral with regard to jurisdictional claims in published maps and institutional affiliations.

\section{Author details}

'Department of Clinical Epidemiology, Aarhus University Hospital, Olof Palmes Allé 43-45, 8200 Aarhus N, Denmark. ${ }^{2}$ Department of Anesthesiology and Intensive Care Medicine, Aarhus University Hospital, Brendstrupgaardsvej 100, 8200 Aarhus N, Denmark. ${ }^{3}$ Department of Anesthesiology and Intensive Care Medicine, Viborg Regional Hospital, Heibergs Alle 4, 8800 Viborg, Denmark. ${ }^{4}$ Department of Epidemiology, Gillings School of Global Public Health, University of North Carolina, Chapel Hill, NC, USA.

\section{Received: 7 September 2017 Accepted: 29 November 2017}

\section{Published online: 28 December 2017}

\section{References}

1. Hoste EA, Bagshaw SM, Bellomo R, Cely CM, Colman R, Cruz DN, Edipidis K, Forni LG, Gomersall CD, Govil D, et al. Epidemiology of acute kidney injury in critically ill patients: the multinational AKI-EPI study. Intensive Care Med. 2015;41:1411-23.

2. De Corte W, Dhondt A, Vanholder R, De Waele J, Decruyenaere J, Sergoyne V Vanhalst J, Claus S, Hoste EA. Long-term outcome in ICU patients with acute kidney injury treated with renal replacement therapy: a prospective cohort study. Crit Care. 2016;20:256.

3. Liborio AB, Leite $T$, Neves FM, Teles F, Bezerra CT. AKI complications in critically ill patients: association with mortality rates and RRT. Clin J Am Soc Nephrol. 2015;10:21-8

4. Nisula S, Kaukonen KM, Vaara ST, Korhonen AM, Poukkanen M, Karlsson S, Haapio M, Inkinen O, Parviainen I, Suojaranta-Ylinen R, et al. Incidence, risk factors and 90-day mortality of patients with acute kidney injury in Finnish intensive care units: the FINNAKI study. Intensive Care Med. 2013:39:420-8.

5. Gammelager $H$, Christiansen $C F$, Johansen MB, Tonnesen $E$, Jespersen $B$, Sorensen HT. Five-year risk of end-stage renal disease among intensive care patients surviving dialysis-requiring acute kidney injury: a nationwide cohort study. Crit Care. 2013;17:R145

6. Palevsky PM, Zhang JH, O'Connor TZ, Chertow GM, Crowley ST, Choudhury D, Finkel K, Kellum JA, Paganini E, Schein RM, et al. Intensity of renal support in critically ill patients with acute kidney injury. N Engl J Med. 2008:359:7-20.

7. Uchino S, Kellum JA, Bellomo R, Doig GS, Morimatsu H, Morgera S, Schetz M, Tan I, Bouman C, Macedo E, et al. Acute renal failure in critically ill patients: a multinational, multicenter study. JAMA. 2005;294:813-8.

8. Chawla LS, Eggers PW, Star RA, Kimmel PL. Acute kidney injury and chronic kidney disease as interconnected syndromes. N Engl J Med. 2014;371:58-66.

9. Bagshaw SM, Lamontagne F, Joannidis M, Wald R. When to start renal replacement therapy in critically ill patients with acute kidney injury: comment on AKIKI and ELAIN. Crit Care. 2016;20:245.

10. Bagshaw SM, Darmon M, Ostermann M, Finkelstein FO, Wald R, Tolwani AJ, Goldstein SL, Gattas DJ, Uchino S, Hoste EA, et al. Current state of the art for renal replacement therapy in critically ill patients with acute kidney injury. Intensive Care Med. 2017;43(6):841-54.

11. Wierstra BT, Kadri S, Alomar S, Burbano X, Barrisford GW, Kao RL. The impact of "early" versus "late" initiation of renal replacement therapy in critical care patients with acute kidney injury: a systematic review and evidence synthesis. Crit Care. 2016;20:122.

12. Zou H, Hong $\mathrm{O}, \mathrm{Xu} \mathrm{G}$. Early versus late initiation of renal replacement therapy impacts mortality in patients with acute kidney injury post cardiac surgery: a meta-analysis. Crit Care. 2017:21:150.

13. Bhatt GC, Das RR. Early versus late initiation of renal replacement therapy in patients with acute kidney injury - a systematic review \& meta-analysis of randomized controlled trials. BMC Nephrol. 2017;18:78.

14. Yang XM, Tu GW, Zheng JL, Shen B, Ma GG, Hao GW, Gao J, Luo Z. A comparison of early versus late initiation of renal replacement therapy for acute kidney injury in critically ill patients: an updated systematic review and meta-analysis of randomized controlled trials. BMC Nephrol. 2017;18:264.

15. Park JY, An JN, Jhee JH, Kim DK, Oh HJ, Kim S, Joo KW, Oh YK, Lim CS, Kang SW, et al. Early initiation of continuous renal replacement therapy improves survival of elderly patients with acute kidney injury: a multicenter prospective cohort study. Crit Care. 2016:20:260.

16. Carl DE, Grossman C, Behnke M, Sessler CN, Gehr TW. Effect of timing of dialysis on mortality in critically ill, septic patients with acute renal failure. Hemodial Int. 2010;14:11-7.

17. Schmidt M, Pedersen L, Sorensen HT. The Danish civil registration system as a tool in epidemiology. Eur J Epidemiol. 2014;29:541-9.

18. Kidney Disease: Improving Global Outcomes (KDIGO) Acute Kidney Injury Work Group. KDIGO clinical practice guideline for acute kidney injury. Kidney Int Suppl. 2012;2:132

19. Grann AF, Erichsen R, Nielsen AG, Frøslev T, Thomsen RW. Existing data sources for clinical epidemiology: the clinical laboratory information system (LABKA) research database at Aarhus University, Denmark. Clin Epidemiol. 2011;3:133-8.

20. Siew ED, Ikizler TA, Matheny ME, Shi Y, Schildcrout JS, Danciu I, Dwyer JP, Srichai M, Hung AM, Smith JP, et al. Estimating baseline kidney function in hospitalized patients with impaired kidney function. Clin J Am Soc Nephrol. 2012;7:712-9.

21. Kidney Disease: Improving Global Outcomes (KDIGO). Clinical practice guideline for the evaluation and management of chronic kidney disease. Kidney Int Suppl. 2013;3:1-150.

22. Schmidt M, Schmidt SA, Sandegaard JL, Ehrenstein V, Pedersen L, Sorensen HT. The Danish national patient registry: a review of content, data quality, and research potential. Clin Epidemiol. 2015;7:449-90.

23. Gammelager $H$, Christiansen $C F$, Johansen MB, Tonnesen $E$, Jespersen $B$, Sorensen HT. One-year mortality among Danish intensive care patients with acute kidney injury: a cohort study. Crit Care. 2012;16:R124.

24. Vincent JL, Moreno R, Takala J, Willatts S, De Mendonça A, Bruining H, Reinhart CK, Suter PM, Thijs LG, on behalf of the Working Group on SepsisRelated Problems of the European Society of Intensive Care Medicine. The SOFA (sepsis-related organ failure assessment) score to describe organ dysfunction/failure. Intensive Care Med. 1996;22:707-10.

25. Brookhart MA, Wyss R, Layton JB, Sturmer T. Propensity score methods for confounding control in nonexperimental research. Circ Cardiovasc Qual Outcomes. 2013:6:604-11.

26. Austin PC, Stuart EA. Moving towards best practice when using inverse probability of treatment weighting (IPTW) using the propensity score to estimate causal treatment effects in observational studies. Stat Med. 2015; 34:3661-79.

27. Cole SR, Hernan MA. Constructing inverse probability weights for marginal structural models. Am J Epidemiol. 2008;168:656-64.

28. Sturmer T, Rothman KJ, Avorn J, Glynn RJ. Treatment effects in the presence of unmeasured confounding: dealing with observations in the tails of the propensity score distribution - a simulation study. Am J Epidemiol. 2010; 172:843-54

29. Gaudry S, Hajage D, Schortgen F, Martin-Lefevre L, Pons B, Boulet E, Boyer A, Chevrel G, Lerolle N, Carpentier D, et al. Initiation strategies for renal-replacement therapy in the intensive care unit. N Engl J Med. 2016:375(2):122-33.

30. Zarbock A, Kellum JA, Schmidt C, Van Aken H, Wempe C, Pavenstadt H, Boanta A, Gerss J, Meersch M. Effect of early vs delayed initiation of renal replacement therapy on mortality in critically ill patients with acute kidney injury: the ELAIN randomized clinical trial. JAMA. 2016;315:2190-9.

31. Siew ED, Matheny ME, Ikizler TA, Lewis JB, Miller RA, Waitman LR, Go AS Parikh CR, Peterson JF. Commonly used surrogates for baseline renal function affect the classification and prognosis of acute kidney injury. Kidney Int. 2010;77:536-42

32. Bagshaw SM, Uchino S, Cruz D, Bellomo R, Morimatsu H, Morgera S, Schetz M, Tan I, Bouman C, Macedo E, et al. A comparison of observed versus estimated baseline creatinine for determination of RIFLE class in patients with acute kidney injury. Nephrol Dial Transplant. 2009;24:2739-44.

33. Zavada J, Hoste E, Cartin-Ceba R, Calzavacca P, Gajic O, Clermont G, Bellomo R, Kellum JA. A comparison of three methods to estimate baseline creatinine for RIFLE classification. Nephrol Dial Transplant. 2010;25:3911-8. 